\title{
Convergent discoidal sand dollars from isolated regions: A geometric morphometric analyses of Dendraster and Arachnoides
}

\author{
Robert E. Swisher ${ }^{1,2, *}$ \\ ${ }^{1}$ Department of Geosciences, National Taiwan University, Taipei City, Taiwan \\ ${ }^{2}$ Sam Noble Museum of Natural History, University of Oklahoma, USA
}

\begin{abstract}
Article history:
Received 5 April 2021

Revised 10 October 2021

Accepted 19 October 2021

Keywords:

Sand dollars, Ontogeny, Geometric morphometrics, Clypeasteroida

Citation:

Swisher, R. E., 2021: Convergent discoidal sand dollars from isolated regions: A geometric morphometric analyses of Dendraster and Arachnoides. Terr. Atmos. Ocean. Sci., 32, 1117-1130, doi: 10.3319/ TAO.2021.10.19.02
\end{abstract}

\begin{abstract}
Sand dollars (Clypeasteroids) have developed a unique discoidal morphology along the perimeter curvature or ambitus. The distinctive round and flattened morphology appears adaptive to their shallow water habitat and appears in multiple species throughout the group. This analysis applies geometric morphometric analysis to fossil clypeasteroid specimens from the genus Dendraster from the western United States coastline, California, and examines the following: (1) Quantifying morphological, ontogenetic, and developmental variation between the clypeasteroid genera Dendraster and Arachnoides; (2) Quantifying discoidal morphology, petaloid structures, and posterior morphological variation within and between the examined genera; (3) Assessing how regional endemicity may effect variation between and within the assessed Clypeasteroids. This study begins to quantify how this distinctive morphology developed in fossil and extant clypeasteroids and how morphological variation during ontogeny compares between the two clypeasteroid genera. Variation is concentrated at different loci with similar circular adult forms achieved through variable shifts in morphology. Results demonstrate strongest ontogenetic trends occur in the aboral/ oral profiles for the landmark and semilandmark analyses of ambitus morphology and curvature shape. Other morphologic traits including the petaloid structures and posterior profile do not readily demonstrate ontogenetic trends. Interspecific variation or potentially morphological variation due to environmental controls appear to play a larger role in observed morphological variation for these traits. This analysis also demonstrates the utility of geometric morphometric analysis for clypeasteroid genera; building a foundation for broader analysis of discoidal morphologies.
\end{abstract}

\section{INTRODUCTION}

The Clypeasteroida (Agassiz 1835) genus Dendraster, family Scutellidae (Gray 1825), is well documented, among the most common macrobenthic invertebrates of the northeastern Pacific Ocean of the United Stated, and has a rich history of study due to a relatively high species diversity, restricted paleogeographic distribution along the Western North American coast line, and abundance of specimens from the Gulf of California to southeastern Alaska (Beadle 1989, 1991; Mooi 1989, 1997). Though relatively geologically young, ranging from the Late Miocene/Pliocene to the present, 25 species/sub-species are currently recognized including at least four extant species (Agassiz 1872-1874;

\footnotetext{
* Corresponding author

E-mail:fossilfinder12@gmail.com
}

Mortensen 1948; Durham 1955; Raup 1956; Beadle 1989, 1991; Mooi 1997). The extensive Dendraster literature covers a wide range of analyses ranging from descriptive, population analyses, and examination of morphological variation and functionality (O'Neill 1978; Seilacher 1979; Chen and Hsieh 1994; Beadle 1995; Nakamura 1995; Collin 1997; Mooi 1997). Though the group has a wide history of analysis, including examination of the morphology of Dendraster, minimal work examines or focuses on underlying morphological variation within the group, particularly utilizing statistically robust methodologies like geometric morphometric analysis. Morphometric and geometric morphometric assessments of echinoid data sets have been previously conducted, but analysis of clypeasteroids specifically are limited (Moore and Ellers 1993; Schmidinger 
2014; Sievers and Nebelsick 2014; Zachos 2015; Schlüter 2016). As observed in other clypeasteroids, Dendraster has developed a distinctive discoidal/circular morphology along the perimeter curvature or ambitus; though research continues it appears that this distinctive morphology may be adaptive for the high-energy, shallow intertidal settings and a burrowing/current filter feeding life habitat that many clypeasteriods inhabit (O’Neill 1978; Seilacher 1979; Stanton et al. 1979; Telford 1981; Brown 1983; Kanazawa 1992; Cabanac and Himmelman 1996; Saitoh and Kanazawa 2012). The feeding habit of some adult Dendraster species, including $D$. excentricus, is complex. Earlier ontogenetic stages and juveniles do not occupy this same niche or feeding life habit as adults. Adult animals will partially burrow in the sediment, with the test then acting as a hydrodynamic wing so the animal can assume an inclined feeding posture parallel to water flow. Test outline, height (camber), and population density all effect the efficiency of the inclined suspension/filter feeding position (O’Neill 1978).

This study builds from these foundational works and attempts to more rigorously quantify ontogenetic and morphological variation in Dendraster by applying geometric morphometric methodologies developed for the examination of extant clypeasteroid echinoids, specifically the genus Arachnoides, and applies them to fossil specimens from the clypeasteroid genus Dendraster; the first application of these methods using a fossil clypeasteroid data set (Swisher and Lin 2019). The analysis also quantifies developmental, ontogenetic, and morphological variation within clypeasteroid genera by comparing the previously analyzed Arachnoides data set, with the newly assessed Dendraster collections. This study also expands work on the previously conducted Arachnoides research and furthers examination of morphological and ontogenetic variation in clypeasteroids by presenting new examinations the posterior profile for clypeasteroid data sets.

Interestingly, these two genera are endemic to and paleogeographically isolated to separate sides of the Pacific Ocean, with Dendraster isolated to the eastern Pacific along the western coast of the United States, and Arachnoides is isolated to portions of the western Pacific (McNamara et al. 2017; Schultz 2017; Lee et al. 2019). This analysis will also explore the role paleogeographic isolation plays on observed morphological and ontogenetic variation within and between the two genera.

The goals of this analysis are: (1) To demonstrate the application of geometric morphometric methods to fossil clypeasteroid data sets by using Dendraster as an example set; (2) To assess and compare morphological, ontogenetic, and developmental variation between the clypeasteroid genera, specifically Dendraster and Arachnoides; (3) To assess and compare how similar circular adult body morphology is similarly or disparately developed between the two clypeasteroid genera, and the implications for development of this morphology in other clypeasteroids; (4) To assess and compare how posterior morphologies vary between clypeasteroid genera morphologically, ontogenetically, and developmentally, using the afore mentioned data sets; (5) To discern the role that geographic isolation, or regional endemicity, may play in observed morphological and developmental variation between and within the two genera.

\section{METHODOLOGY}

\subsection{Study Samples}

This analysis quantifies ambitus curvature or outline shape, petaloid shape, and posterior view curvature variation from the ambitus to vertical apex at the apical disc through digitization of landmark and semilandmark points for Dendraster ashleyi. It then compares morphological variation between a previously examined and expanded data set for Arachnoides placenta. The landmark and semilandmark points used for the Arachnoides data set are modified from previously reported data (Swisher and Lin 2019) for comparison with the new, fossil clypeasteroid, Dendraster data set.

Geometric morphometric analysis is a set of mathematical approaches to quantify and describe the shape and spatial relationship of an organism and its features based the organism's inherent geometry (Savriama 2018; Savriama and Gerber 2018). This analysis uses a landmark and semilandmark based approach to describe an organism's geometry. Landmarks are Cartesian points in 2D or 3D that can be identified without ambiguity repeatedly on a specimen and across a data set; they are fixed, homologous features or structures (Savriama 2018; Savriama and Gerber 2018).

The Dendraster ashleyi fossil data set consists of the NTUG-EUS 2598 collections from the coast of California, U.S.A., housed at the Department of Geosciences, National Taiwan University, museum collections (NTUG). Two sets were examined in this analysis, a smaller ontogenetic series of pristine specimens requiring no preparatory work before analysis and a larger ontogenetic series sampled from a bulk collection that required further preparation before analysis. The pristine ontogenetic series consists of 11 individuals. A total of 39 specimens labeled EUS 2598-001 through EUS 2598-039 were selected from the bulk collection for preparation and analysis; comprising an ontogenetic series from smaller juveniles to full adult morphotypes. Samples range in size from approximately $1.4 \mathrm{~cm}$ in juvenile forms to approximately $6 \mathrm{~cm}$ in adults. Specimens were selected based on completeness and availability of morphological traits required for the landmark and semilandmark based analyses. Specimens examined in the analysis included at least one complete half where landmark and semilandmark data points could be digitized and no readily apparent taphonomic distortion was present.

Information on the Arachnoides placenta data set 
(NTUG-SD-AP-101 to NTUG-SD-AP-126) housed at the Department of Geosciences, National University of Taiwan (NTUG) and used for geometric morphometric comparison with the Dendraster ashleyi data set can be found in Swisher and Lin (2019). The current analysis expands on previous Arachnoides research by including new digitization of the posterior view for the NTUG data set.

Morphology terminology used in this study follows standard practices as illustrated in Mooi (1989). Ambitus curvature is the outline shape of the specimen in aboral or oral view and can be thought of as the perimeter shape or cur- vature outline of the specimen (Swisher and Lin 2019). This is illustrated in Fig. 1 where data points follow along the ambitus outline or curvature of specimens. Methodologies and landmark/semilandmark configurations follows procedures previously described for the Arachnoides data set with some modifications described below for comparative purposes and the newly assessed posterior profile. Analyses of morphological, ontogenetic, and ambitus curvature variation in the Dendraster ashleyi and Arachnoides placenta data sets were conducted using geometric morphometric procedures presented in Bookstein (1991), Zelditch et al. (2004), and

\section{Arachnoides}
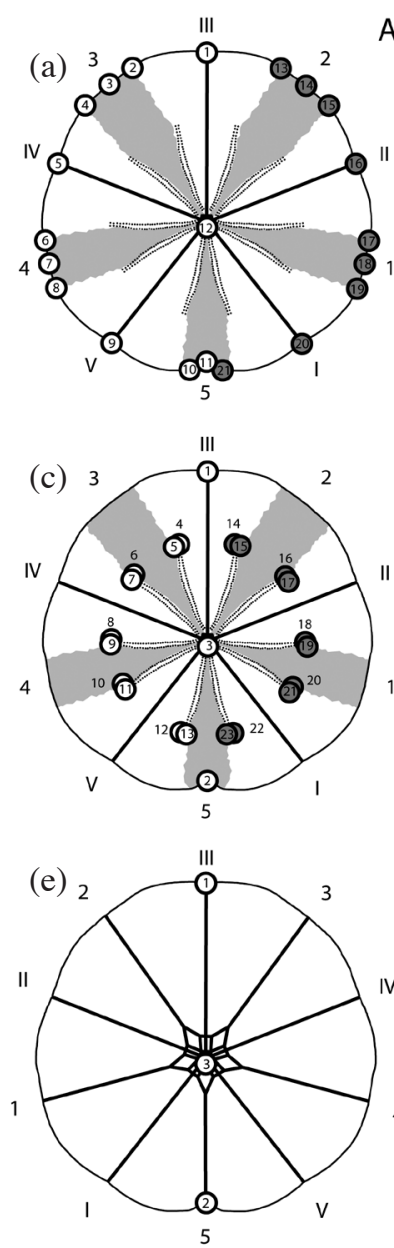

\section{Dendraster}
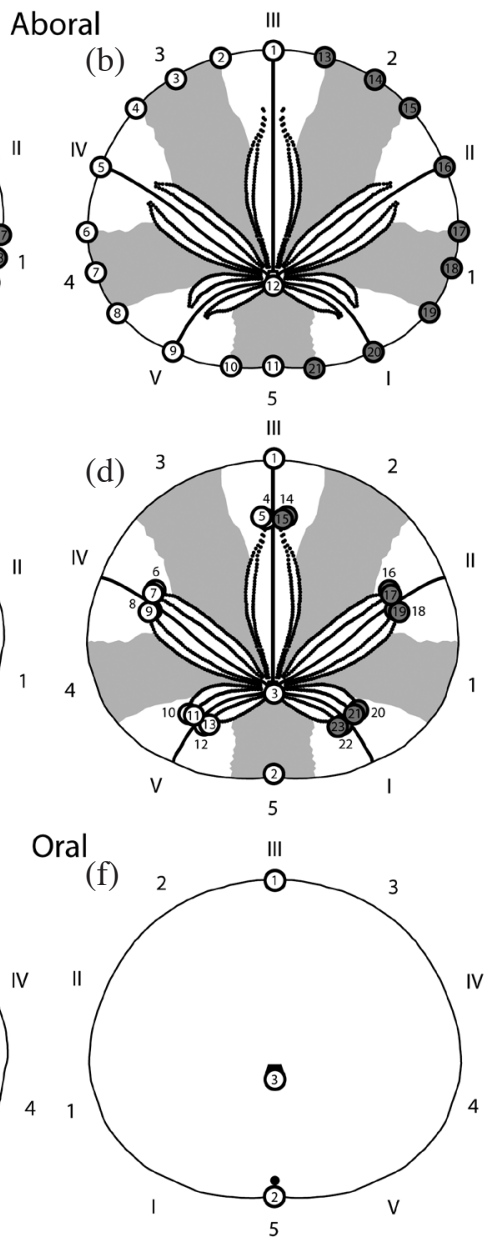

Fig. 1. Landmark and semilandmark configuration for geometric morphometric analysis of Arachnoides placenta, Dendraster ashleyi, and comparative data sets, aboral and oral views. (a) Landmark data points for Arachnoides and Dendraster aboral view, ambitus curvature. (1) Anterior most perradial and ambitus juncture in the ambulacral region (III); (2) - (4) anterior most adradial suture and ambitus intersection points with landmark 3 at the intersection of the ambitus and interradial suture in the interambulacral region (3); (5) lateral intersection of the ambitus and perradial suture in the ambulacral region (IV); (6) - (8) lateral adradial suture and ambitus intersection points with landmark 7 at the intersection of the ambitus and interradial suture in the interambulacral region (4); (9) posterior intersection of the ambitus and perradial suture in the ambulacral region (V); (10) adradial suture on the left-side of the plate boundary in the interambulacral area (5); (11) posterior margin at the interradial suture (5); (12) midpoint taken at the posterior end of the apical disc; (13) - (21) grey circles, are paired with homologous landmarks 2 - 10, white circles. (b) Landmark data points for Arachnoides and Dendraster aboral view, petaloids. (1) Anterior most perradial and ambitus juncture in the ambulacral region (III); (2) posterior margin at the interradial suture (5); (3) midpoint taken at the posterior end of the apical disc; (4) - (13) paired landmarks indicating the distal pore pairs in the ambulacral areas; (14) - (23) grey circles, are paired with homologous landmarks 4 - 13, white circles. (c) Landmark data points for Arachnoides and Dendraster oral view. (1) Anterior most perradial and ambitus juncture in the ambulacral region; (3) posterior margin at the interradial suture; (2) posterior margin of the oral opening. 
Webster and Sheets (2010) and implemented in Swisher and Lin (2019). For aboral view analysis specimens were oriented parallel to the bilateral plane of symmetry with periproct positioned posteriorly for digital photography (Figs. 1a - c). For lateral analysis specimens were oriented perpendicular to the bilateral plane of symmetry with periproct positioned to the left for digital photography (Fig. 2a). For posterior analysis specimens were oriented parallel with the bilateral plane of symmetry with periproct positioned towards the lens for digital photography (Fig. 2b).

TpsDig 2.31 software was used to digitize landmark and semilandmark data points in aboral, and posterior views (Rohlf 2015, 2018). Landmark points were chosen following methodologies outline in Swisher and Lin (2019) to maximize observable morphological variation at plate boundaries, summarize ambitus curvature, quantify petaloid shape, and allow homologous point comparison between the Arachnoides and Dendraster data sets.

Shape variation of the D. ashleyi data set and comparisons made with the A.placenta data set are quantified and visually compared through principal component analysis (PCA) and generated thin-plate spline deformation grids (Rohlf 1990; Bookstein 1991; Zelditch et al. 2004). This analysis also focused on applying previously developed methodologies for comparisons between fossil and extant clypeasteroid data sets. Tests for asymmetry between clypeasteroid data sets is currently beyond the scope of the analysis.

Similarly to the previous Arachnoides analysis, (Swisher and Lin 2019) this study only assesses morphological and ontogenetic variation present within the two examined genera and compares between the data sets. This analysis does not assess asymmetry within the data sets due to assumed approximate bilateral symmetry for this comparative analysis (Zelditch et al. 2004). Asymmetry exists, to some degree, in all biological data sets; this study does not dispute that asymmetry is present in even the approxi- mately bilaterally data sets examined here, but focuses on generic level comparison of morphological and ontogenetic variation. Therefore, assessment of asymmetry within the data sets in beyond the scope of this study. As further described in the procedures below, the left sides in aboral view were primarily used unless specimen were otherwise damaged or incomplete. With landmarks primarily taken from the left side, when applicable, any potential asymmetry effects were reduced. Landmark and semilandmark points digitized for the analysis in aboral, oral, and posterior views are described (Figs. 1 - 2). Descriptive and comparative assessment of ontogenetic and morphological variation within and between the data sets was conducted through principle components analyses (PCA) of landmark and curvature data and visual comparison of thin-plate warp spline deformation grids for examined profiles (Figs. 3 - 10). Digitized landmark and ambitus curvature data were examined using Integrated Morphometrics Package (IMP) software CoordGen8 and PCAGen8 (Sheets 2001; Zelditch et al. 2004, 2012).

Specimens from the EUS 2958 Dendraster ashleyi required preparation using brushing and abrasive papers to remove surrounding sand and reveal morphologic traits. Due to the abrasive sanding procedure used to observe morphological features in the Dendraster data and the risk of damaging fossil material only the left sides of specimens were typically prepared completely for observation and quantification for landmark and semilandmark analysis. The preparation procedure was used to clearly identify homologous points, margins, plate boundaries, structures, and podial pore features for analysis. This procedure reduced the potential for breakage and damage to the specimen, while providing a complete suite of landmark based morphological features for analysis due to the assumed bilateral symmetry in the Dendraster data set. Approximate bilateral symmetry is assumed for the Dendraster and Arachnoides data sets due to the approximate bilaterally nature of the test; asymmetry does exist to some degree within the data

\section{Arachnoides}

\section{Dendraster}

\section{Lateral}

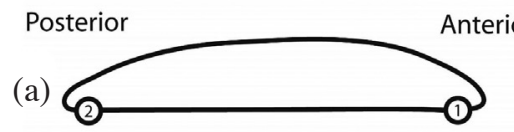

(b)
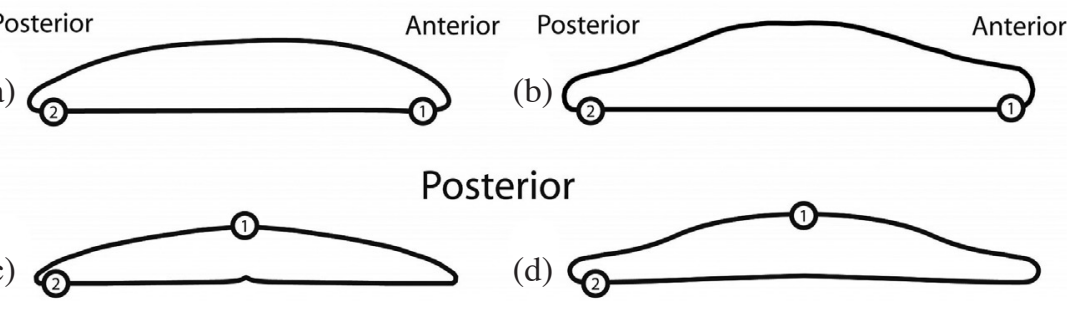

Posterior

(c)

(d)

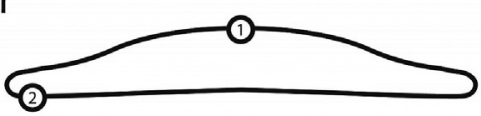

Fig. 2. Landmark and semilandmark configuration for geometric morphometric analysis of Arachnoides placenta, Dendraster ashleyi, and comparative data sets, lateral and posterior views. (a) Landmark and semilandmark data points for Arachnoides and Dendraster, and lateral view. (1) Anterior most juncture with anterior margin curvature; (2) posterior most juncture with anterior margin curvature. (b) Landmark and semilandmark data points for A. placenta, and D. ashleyi posterior view. (1) Apex of aboral surface along mid-line body axis of bilateral symmetry; (2) lateral most juncture with lateral margin curvature. 

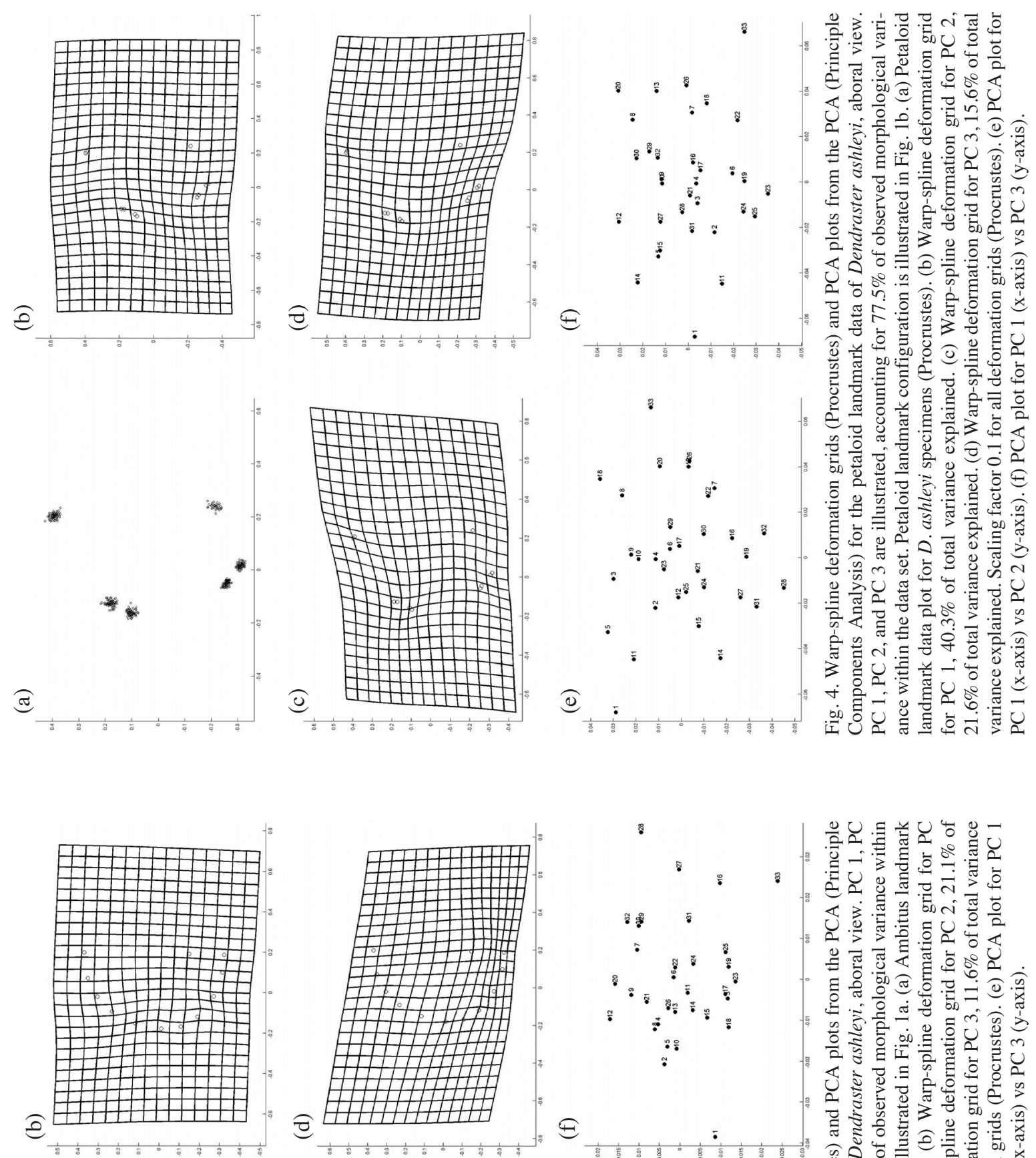

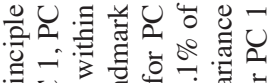

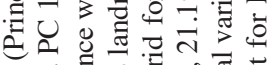

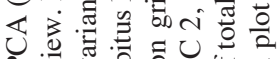

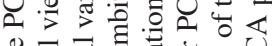

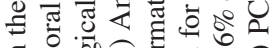

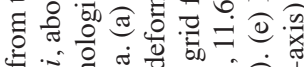

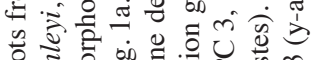

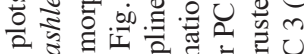

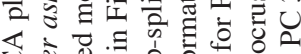

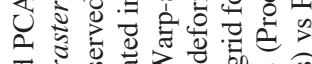
สี ชิ 药

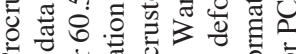
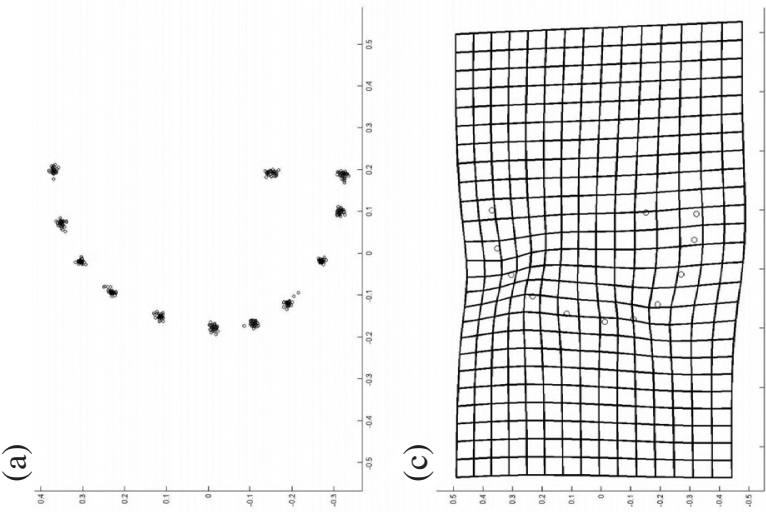

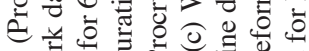

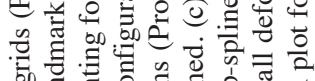

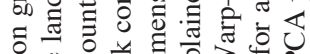

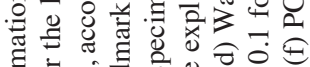

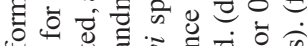
की

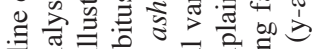

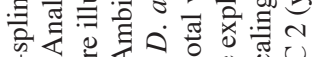
करें

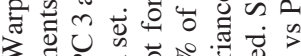
उ. ญ

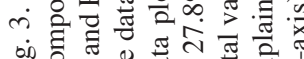



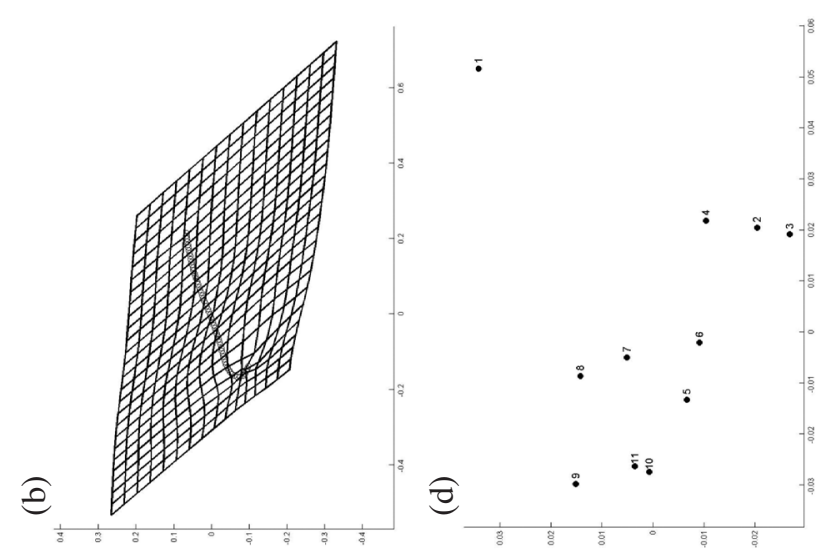

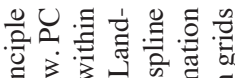

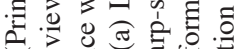

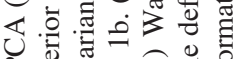

\&

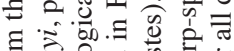

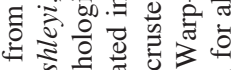

을 仓े

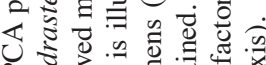

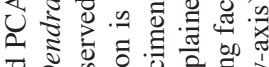

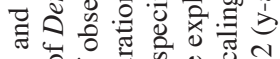

बิ 0 जै

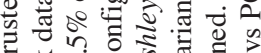

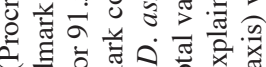
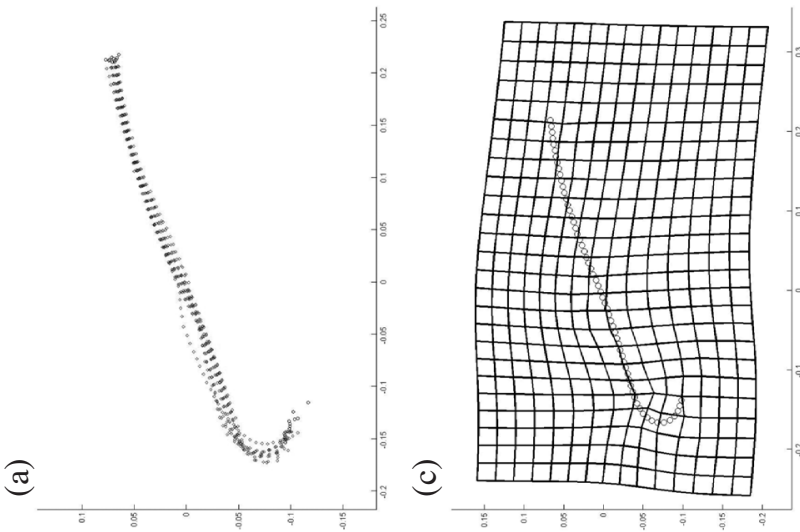

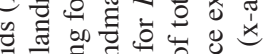

क力

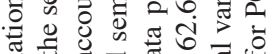

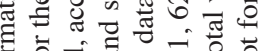

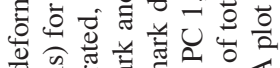

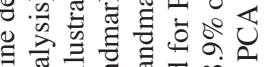

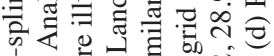

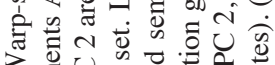

i.

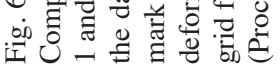
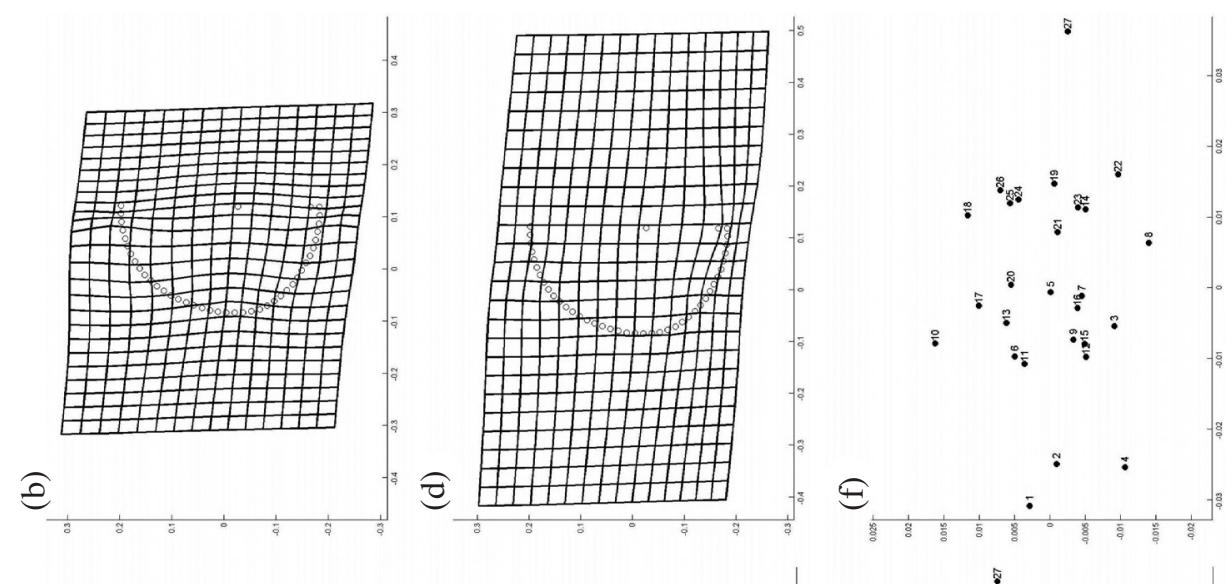

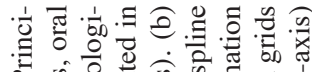

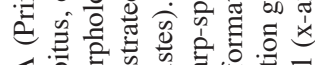

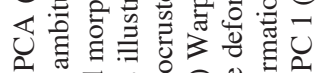

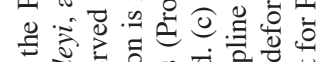
है

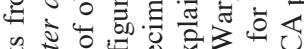

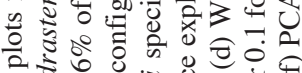

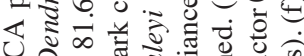

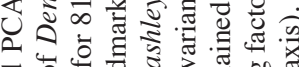

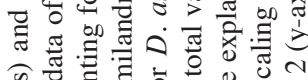
㟧

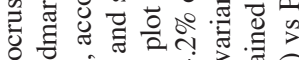
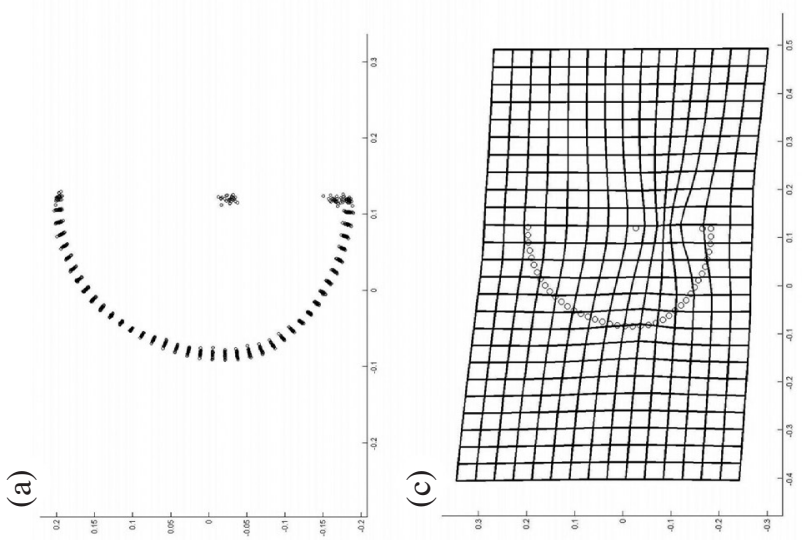

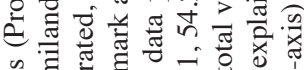

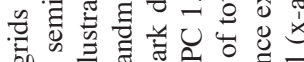

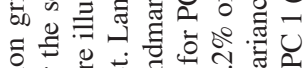

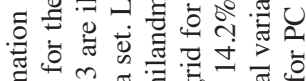

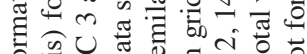

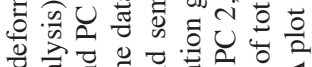

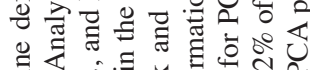

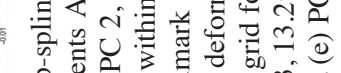
记 3 हो का

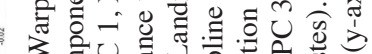

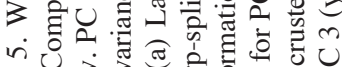
कि 

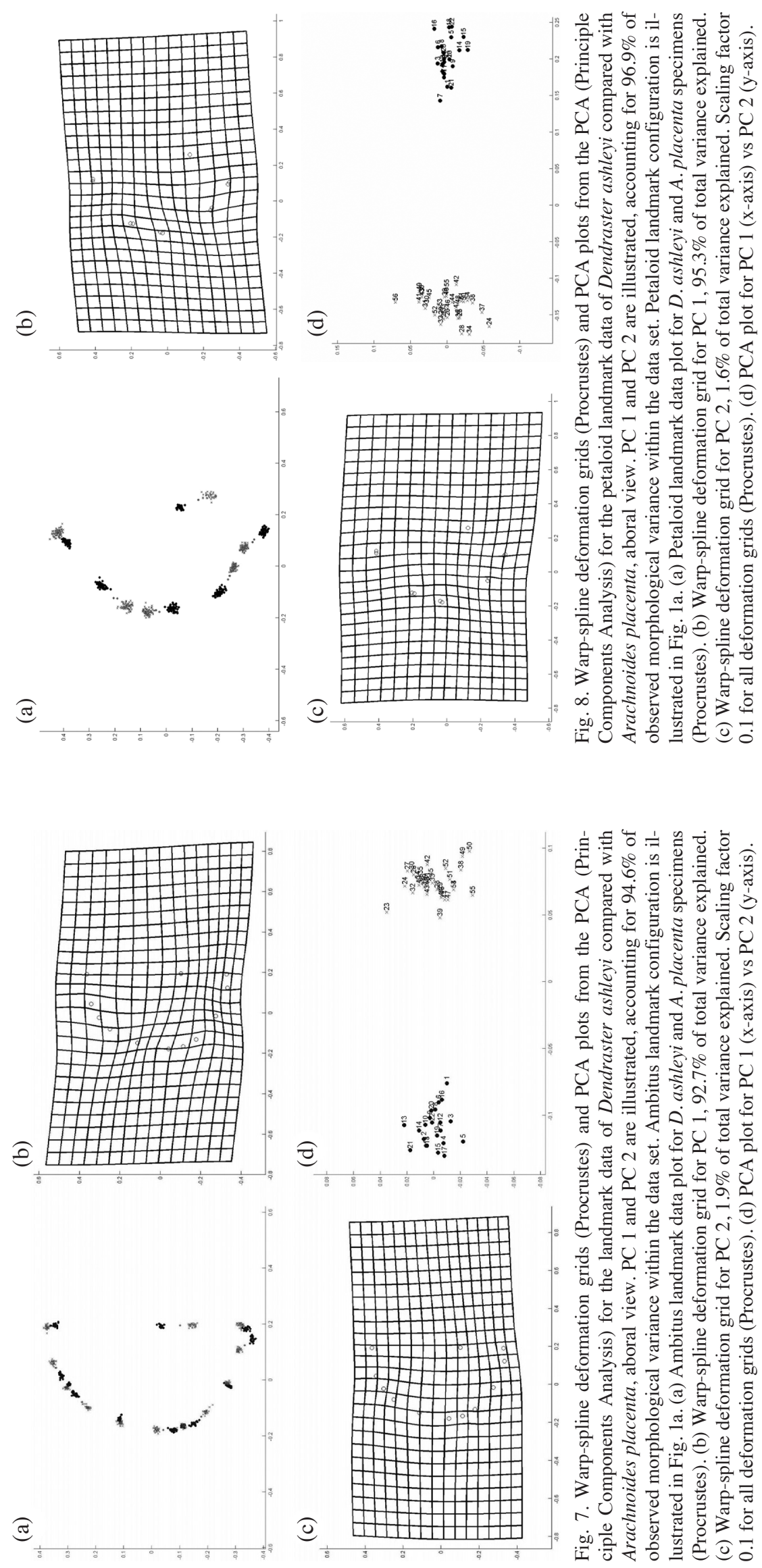

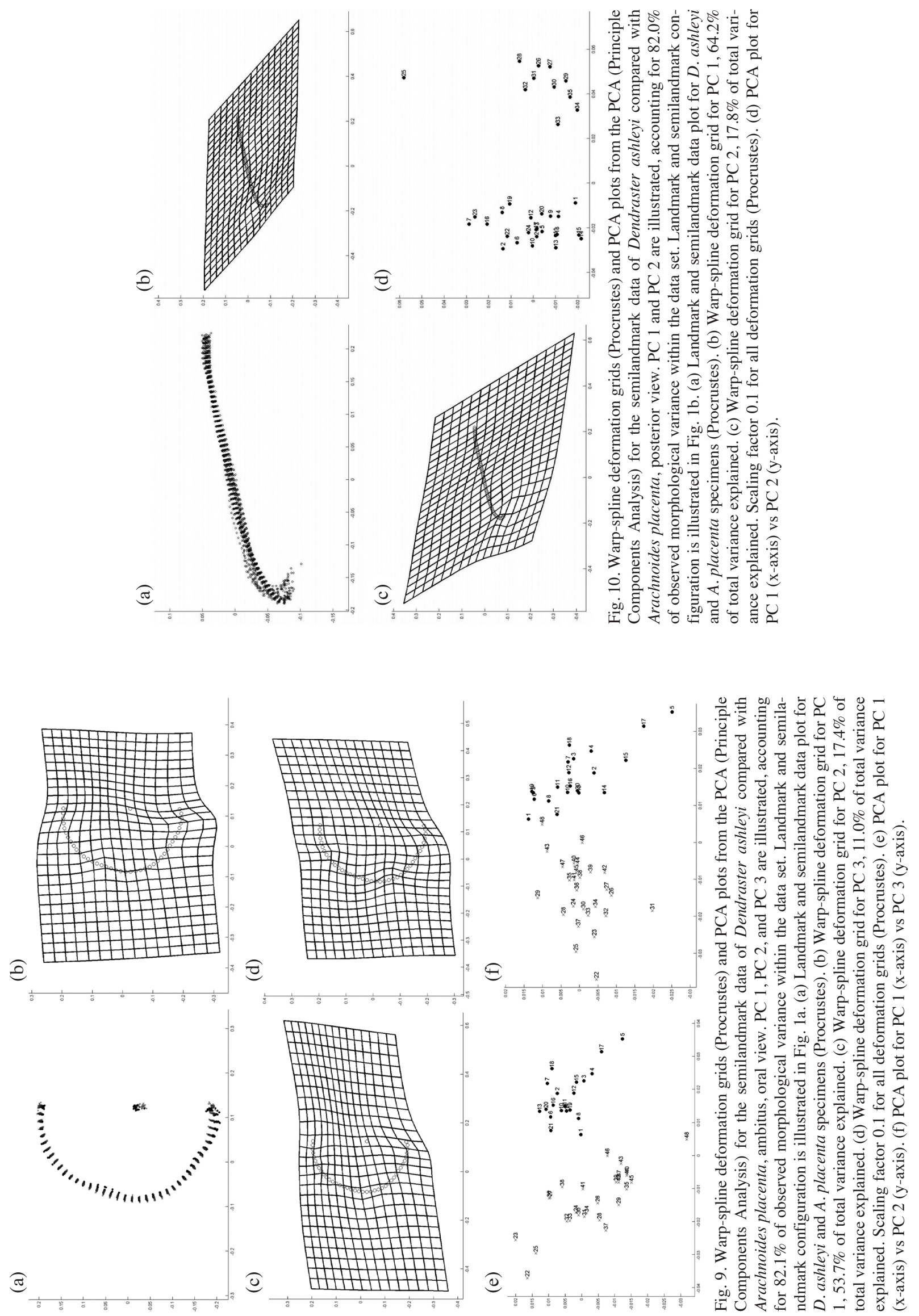
sets but the focus of the analysis remains on morphological shape change during ontogeny and broad comparisons at a generic level between the genera, not higher resolution intra-specific morphological variation due to asysmmetry. Similar to asymmetry, intra-specific variation is also present to some degree, as with any biological data set; the sample sizes used for the analysis help to average and minimize the impact of these factors for the broader comparisons examined in this study. This methodology is in part implemented when both sides of the specimens were available for digitization and quantification; landmark points on both sides of the axial plane were mirrored across the axis following procedures outlined in Zelditch et al. (2004) and Zelditch (2005) since they cannot be regarded as independent. This analysis focuses on shape and curvature variation within Dendraster and generic level morphological comparisons between the Dendraster and Arachnoides data sets and not on asymmetry between data sets; as such including information on both the left and right sides of approximately bilaterally symmetrical specimens would be redundant and beyond the scope of the current morphological analysis (Zelditch et al. 2004). Defined landmarks to assess ambitus curvature shape change/outline shape variation are based on broadly define homologues features present between the examined genera; specifically, the ambitus and its intersection with the ambulacral and interambulacral suture. These intersections are broadly defined fixed homologous points chosen for generic level comparison in this analysis and to facilitate future comparative studies with other clypesteroid genera as they can be readily identified throughout the group.

The mirroring procedure averages any variations present between the right and left halves of the specimen. While some degree of asymmetry is typical for biological data sets and asymmetry between the right and left halves can present strongly in some clypeasteroid data sets, strong test abnormalities were excluded from this study (Collin 1997); future studies will attempt to quantify asymmetry between data sets, species, and other clypesteriod genera, but at this time is beyond the scope of the current study of morphological variation comparison between the examined genera.

\subsection{Landmark Analysis of Aboral Surface}

A total of 12 landmarks were digitized in aboral view (Fig. 1a): 3 landmarks along the axis (points 1, 11, and 12 in Fig. 1a); 9 paired ambitus landmarks on the left side of the axis (points 2 - 10 in Fig. 1a); Point 1 is at the junction of the perradial suture with ambitus in ambulacral region III. Point 11 is at the junction of the interradial suture with ambitus in interambulacral region 5. Point 12 is placed at the posterior margin of the apical disc. Points 2, 4, 6, 8, 10 are placed at the junction of the adradial sutures with ambitus. Points 3 and 7 are placed at the junction of the interradial sutures with ambitus. Points 5 and 9 are placed at the junction of the perradial sutures with ambitus.

\subsection{Landmark Analysis of Aboral Surface, Petaloid Structures}

A total of 11 landmarks were digitized in aboral view (Fig. 1b): Point 1 is placed at the posterior margin of the apical disc. Points 2 - 11 are placed at the distal positions of the petaloids based on the last distinguishable podial pore pairs (Fig. 1b). Previous quantitative work supports that the petaloid structures of clypeasteroids maintain relative bilateral symmetry, even if asymmetry is present within the structure, and petaloid points have been successfully used and assessed in a previous geometric morphometric analysis (Lawrence et al. 1998; Swisher and Lin 2019).

\subsection{Semilandmark Analysis of Oral Surface}

A total of 3 landmarks were digitized in aboral view (Fig. 1c), utilizing the ambitus landmark configuration described in the aboral view landmark analysis (Fig. 1a). 2 landmarks along the axis (points 1 and 2 in Fig. 1c). A total of 40 semilandmarks were digitized, along the ambitus for summarization of specimen curvature; bounded by landmark data points (Fig. 1c). All semilandmark data are bounded by landmark data points, landmarks 1 - 2 (Fig. 1c). The semilandmark analysis was based on data collected from the left side of the specimen for comparison with landmark analyses and between clypeasteroid data sets.

\subsection{Semilandmark Analysis of Posterior View}

A total of two landmarks were digitized in posterior view (Fig. 2). Point 1 is placed at the apex or, maximum height of the aboral surface along the body axis mid-line (Fig. 2). Point 2 is placed at the left lateral edge of the specimen, at the base of anterior ambitus curvature along the horizontal oral surface plane (Fig. 2). A total of 60 semilandmarks were digitized, along the aboral margin in posterior view. All semilandmark data are bounded by landmark data points, landmarks 1 - 2 (Fig. 2). The semilandmark analysis was based on data collected from the left side of the specimen for comparison with landmark analyses and between clypeasteroid data sets.

\section{RESULTS}

Quantified morphological variation of the Dendrster ashleyi data set and comparisons made with the Arachnoides placenta data set were conducted through Principal Component Analysis (PCA) for the digitized ontogenetic series of the $D$. ashleyi and A. placenta data sets for the landmark analyses in aboral views, and semilandmark analyses in aboral and posterior views are presented in Tables 1,2 , and illustrated in Figs. 3 - 10. 
Table 1. Principle Component Analyses percentages for Dendraster ashleyi. PC1 - PC3 and sum of variation for landmark, petaloid, and semilandmark analyses.

\begin{tabular}{ccccc}
\hline Dendraster & PC1 & PC2 & PC3 & Sum \\
\hline Landmark, left side ambitus & $27.8 \%$ & $21.1 \%$ & $11.6 \%$ & $60.5 \%$ \\
Landmark, left side petaloid & $40.3 \%$ & $21.6 \%$ & $15.6 \%$ & $77.5 \%$ \\
Semilandmark analysis, posterior view & $62.6 \%$ & $28.9 \%$ & - & $91.5 \%$ \\
\hline
\end{tabular}

Table 2. Principle Component Analyses percentages for comparative analyses of Arachnoides placenta and Dendraster ashleyi. PC1-PC3 and sum of variation for landmark, petaloid, and semilandmark analyses.

\begin{tabular}{ccccc}
\hline Arachnoides vs Dendraster & PC1 & PC2 & PC3 & Sum \\
\hline Landmark, left side ambitus & $92.7 \%$ & $1.9 \%$ & - & $94.6 \%$ \\
Landmark, left side petaloid & $95.3 \%$ & $1.6 \%$ & - & $96.9 \%$ \\
Semilandmark analysis, posterior view & $64.2 \%$ & $17.8 \%$ & - & $82.0 \%$ \\
\hline
\end{tabular}

\subsection{Dendraster}

\subsubsection{PCA of Landmark Analysis of Aboral Surface}

The plot of PC 1 vs. PC 2 quantifies an ontogenetic clustering controlled by PC 1 . PC 1 differentiates smaller specimen towards the right and larger specimen towards the left of the plot. PC 2 and PC 3 are more randomly distributed, with no apparent ontogenetic trends. Deformation depicted in PC 1 is concentrated along the ambitus at the lateral perradial sutures (Fig. 3b). Deformation depicted in PC 2 is again concentrated along the ambitus at the lateral perradial sutures and interradial sutures, with deformation developed more strongly anteriorly (Fig. 3c). Deformation is also depicted along the lateral, posterior facing, adradial suture and along the posterior ambitus margin (Figs. 3c, e, f). Deformation depicted in PC 3 is strongly developed along the posterior ambitus margin and interiorly (Figs. 3d, e, f).

\subsubsection{PCA of Semilandmark Analysis of Oral Surface}

PC 1 vs. PC 2 plots ontogenetic clustering controlled by PC 1 . PC 1 clusters smaller specimens to the left and larger specimens towards the right of the diagram. PC 2 and PC 3 are more randomly distributed, with no apparent ontogenetic trends. Deformation depicted in PC 1 is concentrated along the axial mid-line/line of bilateral symmetry, with slight deformation noted along the lateral most margins (Fig. 5b). Deformation depicted in PC 2 is concentrated posteriorly, interiorly (Fig. 5c). PC 3 also depicts deformation concentrated posteriorly, but more strongly developed along the posterior ambitus margin (Fig. 5d).

\subsubsection{PCA of Landmark Analysis of Petaloid Structure}

PC 1 vs. PC 2 quantify a small ontogenetic trend differentiated by PC 1 . PC 1 positions the smallest specimen towards the right and largest specimen towards the left of the plot, with intermediate specimens showing no apparent differentiation (Fig. 4e). PC 2 and PC 3 are more randomly distributed, with no apparent ontogenetic trends (Fig. 4f). PC 1 depicts strongest deformation at the lateral-most podial pore pairs, with deformation also noted at the posterior-most podial pore pairing; deformation is perpendicular towards the center of the specimen (Fig. 4b). PC 2 depicts strongest deformation at the lateral-most podial pore pairs, with deformation also noted at the posterior- and anterior-most podial pore pairing; deformation is tangential to the center of the specimen (Fig. 4c). PC 3 depicts strongest deformation at the posterior-most podial pore pairing, with deformation also noted at the lateral-most podial pore pairing (Fig. 4d).

\subsubsection{PCA of Semilandmark Analysis of Posterior View}

Data plots for PC 1 vs PC 2 shows apparent partitioning based on relative body size. Smaller specimens plot towards the right of PC 1 with larger specimen plotting to the left (Fig. 6d). The partitioning of PC 2 is more widely distributed and does appear related to relative body size (Fig. 6d). PC 1 is strongly controlled by lateral margin deformation, with minor deformation along the aboral surface, with the strongest aboral deformation adjacent to the beginning of the lateral margin curvature (Fig. 6b). Deformation in PC 2 is similar to PC 1, but more strongly concentrated along the aboral surface approaching the lateral margin (Fig. 6c). 


\subsection{Comparative Analysis of Dendraster and Arachnoides}

\subsubsection{PCA of Landmark Analysis of Aboral Surface}

When PC 1 vs. PC 2 is plotted two distinct clustering in the data are quantified. PCA 1 separates the Arachnoides and Dendraster data sets, to the left and right respectively (Fig. 7b). PCA 2 distinguishes morphological variation within the genera, with Dendraster showing a larger scattering morphological variation (Fig. 7c). Deformation along PC1 is widely spread across the ambitus, with concentrations at the interradial sutures perpendicular towards the specimen center, and at the adradial/perradial ambitus margins tangential to the ambitus (Fig. 7d). PC2 deformation is similar, but more weakly developed, with deformation at the adradial/interradial ambitus margins tangential to the ambitus more distinctly developed than perradial deformation (Fig. 7d).

\subsubsection{PCA of Semilandmark Analysis of Oral Surface}

The PC 1 vs. PC 2 plot distinguishes two clusters in the data set, through PC 1, though not as widely separated or distinctive as clusters in other comparative analysis between the Arachnoides and Dendraster data sets (Figs. 9b, e). The PC 2 plot shows wider dispersion in the Dendraster data set while the plot of PC 3 shows wider distribution in the Arachnoides data set. Deformation presented in PC 1 is concentrated along the axial mid-line/line of bilateral symmetry and along the lateral most margins between perradial sutures (Figs. 9b, e). Deformation in PC 2 is again concentrated along the axial mid-line/line of bilateral symmetry, but with strong deformation also depicted along the anterior margin (Figs. 9c, e). Deformation in PC 3 is concentrated laterally and anteriorly at distinct points along the ambitus at suture junctions (Figs. 9d, f).

\subsubsection{PCA of Landmark Analysis of Petaloid Structure}

The plot of PC 1 vs. PC 2 depicts two distinct clustering with PCA 1 separating the Arachnoides and Dendraster data sets, to the right and left respectively (Fig. 8b). PCA 2 distinguishes morphological variation within the genera, with Dendraster show wider dispersion in morphological variation (Fig. 8c). Deformation along PC1 concentrated along the lateral margins of the petaloids, relatively uniformly (Fig. 8d). PC2's deformation pattern is with stronger deformation within the petaloids, particularly the lateral and posterior petals (Fig. 8d).

\subsubsection{PCA of Semilandmark Analysis of Posterior View}

The plot of PC 1 vs. PC 2 shows two distinct clustering in the data. PCA 1 separates the Arachnoides and Den- draster data sets, to the left and right respectively (Fig. 10b). PCA 2 distinguishes morphological variation within the genera, with Dendraster show wider dispersion in morphological variation (Fig. 10c). Deformation along PC1 is widely spread, with distinct deformation at the lateral margin and in regions of the aboral surface approaching the lateral margin and midline apex (Fig. 10b). Deformation along PC2 is again widely spread, but most strongly concentrated at the curvature along the lateral margin (Fig. 10c).

\section{DISCUSSION}

Morphological and developmental variation is concentrated at different loci between the two genera examined in this analysis. Dendraster has a more complex developmental and morphological shape change throughout ontogeny when compared with the Arachnoides data set. These results are of particular interest for understanding the complex evolutionary history within and between clypeasteroids. This suggests other clypeasteroids may have independently obtained a discoidal morphological outline. Understanding where convergence has occurred vs. where a true shared evolutionary history of discoidal morphology exists in the clade is an important evolutionary question for clypeasteroids and worth further study. Looking specifically at this study, the observed Dendraster data set also appears to have higher levels of intraspecific variation when compared with the observed Arachnoides dataset, particularly in the "middle" ontogenetic series size ranges, with generally a wider dispersion of data in PCA plots. As a result, the signal for ontogenetic variation in Dendraster is less distinct and harder to distinguish, particularly of the "middle" ontogenetic size ranges when compared with the Arachnoides data set. Larger degrees of morphological variation are reported through the PCA results of the Dendraster data set of the aboral landmark and semilandmark analysis when compared with the Arachnoides data set. Individual PCs (Principle Components) account for smaller percentages of observed morphological variation and more PCs are reported for the Dendraster data set. This suggests that there is a wider skew of morphological variation for the Dendraster data, and while PC 1 recovers an ontogenetic trend, other PC's report this wider degree of observed morphological variation.

The results of this analysis suggest circular or discoidal ambitus and body morphology are variably obtained, or at least secondarily modified, across the clypeasteroid clades in this study, based on comparisons between the Dendraster and Arachnoides data sets. Deformation is strongly concentrated in Arachnoides at suture junctions, particularly the adradial sutures in the interambulacral regions, with stronger deformation anteriorly during ontogeny. Deformation is most apparent in shifts in lateral morphology in Dendraster, but strong deformation is also detected at the perradial sutures. Though both genera obtain discoidal ambitus outlines 
they are derived from completely disparate and distinct ontogenetic paths for ambitus outline shape, with disparately positioned loci for morphological variation. Dendraster is initially more elongate in early ontogeny, becoming nearly circular or discoidal during the middle and later phases of ontogeny, at the latest ontogenetic stages mild lateral expansion is observed in the largest reported specimens, skewing the discoidal shape slightly. The examined Arachnoides data set is initially pentagonal in outline, but during ontogeny deformation at the sutures shifts ambitus morphology to a distinctive circular or discoidal outline. Morphological variation or deformation during ontogeny at sutures margins accompanied with stronger, non-isometric growth patterns anteriorly, appears to be more important for observed adult discoidal shape in Arachnoides, while broader curvature change concentrated at the perradial sutures and due to continued lateral expansion is more important for the observed adult outline in Dendraster. Analysis of the posterior view for Dendraster, Arachnoides, and between the two genera suggests that ontogenetic development had little discernable control on observed morphological variation for the two genera. Intra-specific variation appears to dominate morphological variation in these profiles, while observable ontogenetic trends in morphological variation is distinct in the aboral and oral views. This suggest ambitus or body outline in the aboral/oral views may be more adaptive/selectively controlled for due to trends in morphological development towards similar adaptive shapes, in this case a discoidal outline. Morphological variation in the posterior view appears less selective, with a wider range of morphological variation across ontogeny with no discernable ontogenetic trend, suggesting intra-specific variation, or eco-phenotypical controls may play stronger roles in observed morphological variation in these profiles. Understanding how these factors controlled morphological development and evolutionary history in clypeasteroids provides exciting avenues for future work.

\section{CONCLUSION}

This analysis and its results demonstrate that discoidal ambitus outlines are derived from disparate and distinct ontogenetic pathways, with distinct variation in where and how shape changes during ontogeny and with disparately positioned loci for morphological variation in the assessed clypeasteroid genera Arachnoides and Dendraster. These results raise important questions about the evolutionary origins of this unique morphology within clypeasteroids. What modes of development are present within clypeasteriods and to what degree have other clypeasteriods obtained similar discoidal outlines through distinctive evolutionary origins and disparate methods of morphological variation ending in a similar discoidal/circular ambitus outline? Over-all, the results of this analysis suggest that body outline in aboral/ oral views is highly selected for throughout ontogenetic development in clypeasteroids, particularly for the adult, circular/discoidal morphology. The notable exception is the posterior view analysis for the Dendraster data set, where a strong ontogenetic trend is quantified. This apparent trend follows observations in O'Neill (1978), suggesting Dendraster's profile is highly adapted for hydrodynamic feeding behaviors that shift during ontogeny. This suggests that hydrodynamic shifts during ontogeny, at least in this profile, are more highly adaptive in Dendraster than Arachnoides, and points toward more specialized niche partitioning during ontogeny between the genera. This result is congruent with observations of the relatively unique, up-right feeding position of adult Dendraster specimens and the observed niche partitioning between some extant adult and juvenile Dendraster specimens.

To better understand clypeasteroids, the complex evolutionary radiation within, and independent development of discoidal ambitus across clypeasteroids clades it is imperative that detailed morphometric analyses, such as the ones presented in this analysis, are continued for the group. Clypeasteroids provide a unique opportunity to examine many facets of evolutionary processes, including evolutionary convergence, environmental controls on adaptive morphology in a geologic context, and paleobiogeographic controls like regional edemicity, vicariance, and dispersal; all in a group with a rich geological history, distinctive and quantity morphological traits, and extant members for comparison with extinct fossil taxa. These assets mean that clyapeasteroids can provide a rich source for evolutionary analyses and scientific inquiry that should be taken advantage of to the utmost by researchers.

The circular/discoidal outline appears in multiple clades within clypeasteroid clades, supporting a perceived selective/adaptive importance. The results of this analysis suggests that though the circular/discoidal outlines appear similar in clypeasteroids, they may be independently derived due to dissimilar ontogenetic development trends, at least between the two genera examined in this analysis. While this appears true for the circular/discoidal morphological trends in the examined clypeasteroid data sets, how these trends compare with other clypeasteroids adult morphologies/ambitus outlines beyond circular/discoidal shapes is currently unknown and presents an avenue for future comparative analysis. This also raises the question, how variable is the development of discoidal morphology across clypeasteroids? Future analyses will look at address if the development variation of this distinctive circular morphology, as observed through geometric morphometric techniques in this analysis, agrees with the current phylogenetic understanding of the clypeasteroid clade; assessing the reasons why or why not developmental patterns agree with phylogenetic hypotheses and the implications of independent development of discoidal morphology across the clypeasteroid clade. This 
analysis demonstrates the utility of geometric morphometric applications for differentiating morphological variation and broader generic variation between clypeasteroids, providing a tool set for future comparative analyses between fossil and extant clypeasteroid data sets.

Lastly, the role that paleobiogeography plays in and contributes towards the observed disparate trends in morphological variation between Dendraster and Arachnoides should be explored and quantified further. Specifically, the two genera occur in disparate regions of endemicity, the western Pacific for Arachnoides, and eastern Pacific regions for Dendraster that may have contributed, in part, to observed ontogenetic and morphological variation. The two genera are members of distinct suborders within Clypeasterioda with disparate evolutionary development that likely plays the largest defining role in the observed morphological and ontogenetic trends. However, parsing out to what degree, if any that, that paleobiography, and extend geographic isolation, plays in the observed trends in morphological variation and ontogenetic development within these two genera as well as the observed differences between the genera should continue to be explored.

Acknowledgements This study was funded by Taiwan Ministry of Science and Technology (MOST 107-2811-M002-3125 and MOST 108-2811-M-002-608 to RES; and MOST 108-2116-M-002-014 MOST 109-2116-M-002020 to JPL).

\section{REFERENCES}

Agassiz, A., 1872-1874: Revision of the Echini: Illustrated Catalogue of the Museum of Comparative Zoölogy at Harvard College, 7, pt. 1-2: i-xii, 1-378, pls. 1-49 (1872), pt. 3, 379-628+1, pls. 50-77, (1873), pt. 4, 629762, pls. 78-94, (1874).

Agassiz, L., 1835: Prodrome d'une monographie des radiaires ou Échinodermes. Mémoires de la Société des Sciences Naturelles de Neuchâtel, 1, 168-199.

Beadle, S. C., 1989: Ontogenetic regulatory mechanisms, heterochrony, and eccentricity in Dendrasterid sand dollars. Paleobiology, 15, 205-222, doi: 10.1017/ s0094837300009428. [Link]

Beadle, S. C., 1991: The biogeography of origin and radiation: Dendrasterid sand dollars in the northeastern pacific. Paleobiology, 17, 325-339, doi: 10.1017/ s009483730001068x. [Link]

Beadle, S. C., 1995: Retrodisplacement of the oral and anal openings in dendrasterid sand dollars. Evolution, 49, 1203-1214, doi: 10.2307/2410445. [Link]

Bookstein, F. L., 1991: Morphometric Tools for Landmark Data: Geometry and Biology, Cambridge University Press, Cambridge, 435 pp.

Brown, C. L., 1983: Substrate preference and test morphol- ogy of a sand dollar (Echinarachnius parma) population in the Gulf of Maine. Bios, 54, 246-254.

Cabanac, A. and J. H. Himmelman, 1996: Population structure of the sand dollar Echinarachnius parma in the subtidal zone of the northern Gulf of St. Lawrence, eastern Canada. Can. J. Zool., 74, 698-709, doi: 10.1139/z96-079. [Link]

Chen, C. P. and H. L. Hsieh, 1994: A Basic Guide to Farm Marine Invertebrates, National Museum of Marine Biology and Aquarium, Pingdong, 92 pp. (in Chinese)

Collin, R., 1997: Ontogeny of subtle skeletal asymmetries in individual larvae of the sand dollar Dendraster excentricus. Evolution, 51, 999-1005, doi: 10.2307/2411175. [Link]

Durham, J. W., 1955: Classification of clypeasteroid echinoids. University of California Publications in Geological Sciences, 31, 73-198.

Gray, J. E., 1825: An attempt to divide the Echinida, or Sea Eggs, into natural families. Annals of Philosophy, 10, 423-431.

Kanazawa, K., 1992: Adaptation of test shape for burrowing and locomotion in spatangoid echinoids. Palaeontology, 35, 733-750.

Lawrence, J. M., C. M. Pomory, J. Sonnenholzner, and C.M. Chao, 1998: Bilateral symmetry of the petals in Mellita tenuis, Encope micropora, and Arachnoides placenta (Echinodermata: Clypeasteroida). Invertebr. Biol., 117, 94-100, doi: 10.2307/3226855. [Link]

Lee, H., J.-P. Lin, H.-C. Li, L.-Y. Chang, K.-S. Lee, S.-J. Lee, W.-J. Chen, A. Sankar, and S.-C. Kang, 2019: Young colonization history of a widespread sand dollar (Echinodermata; Clypeasteroida) in western Taiwan. Quat. Int., 528, 120-129, doi: 10.1016/j. quaint.2018.12.003. [Link]

McNamara, K. J., D. L. Pawson, A. D. Miskelly, and M. Byrne, 2017: Class Echinoidea. In: Byrne, M. and T. D. O'Hara (Eds.), Australian Echinoderms: Biology, Ecology and Evolution, CSIRO Publishing, Clayton South, 351-445.

Mooi, R., 1989: Living and fossil genera of the Clypeasteroida (Echinoidea, Echinodermata): An illustrated key and annotated checklist. Smithsonian Contributions to Zoology, Smithsonian Institution Press, doi: 10.5479/ si.00810282.488. [Link]

Mooi, R., 1997: Sand Dollars of the genus Dendraster (Echinoidea: Clypeasteroida): Phylogenetic Systematics, Heterochrony, and Distribution of extant species. Bull. Mar. Sci., 61, 343-375.

Moore, A. M. F. and O. Ellers, 1993: A functional morphospace, based on dimensionless numbers, for a circumferential, calcite, stabilizing structure in sand dollars. J. Theor. Biol., 162, 253-266, doi: 10.1006/ jtbi.1993.1086. [Link]

Mortensen, T., 1948: A Monograph of the Echinoidea: IV.2 
Clypeastroida. Clypeastridae, Arachinoididae, Fibulariidae, Laganidae and Scuteliidae, C.A. Reitzel, Copenhagen, $471 \mathrm{pp}$.

Nakamura, R. K., 1995: Morphological variation in the Pacific sand dollar Dendraster excentricus. Can. J. Zool., 73, 576-583, doi: 10.1139/z95-066. [Link]

O’Neill, P. L., 1978: Hydrodynamic analysis of feeding in sand dollars. Oecologia, 34, 157-174, doi: 10.1007/ bf00345164. [Link]

Raup, D. M., 1956: Dendraster: A problem in Echinoid taxonomy. J. Paleontol., 30, 685-694.

Rohlf, F. J., 1990: Rotational fit (Procrustes) methods. Proceedings of the Michigan Morphometrics Workshop, University of Michigan, Special Publication, Vol. 2, 227-236.

Rohlf, F. J., 2015: The tps series of software. Hystrix It. J. Mamm., 26, 9-12, doi: 10.4404/hystrix-26.1-11264. [Link]

Rohlf, F. J., 2018: TpsDig, digitize landmarks and outlines, version 2.31. Department of Ecology and Evolution, State University of New York at Stony Brook.

Saitoh, M. and K. Kanazawa, 2012: Adaptative morphology for living in shallow water environments in spatangoid echinoids. Zoosymposia, 7, 255-265, doi: 10.11646/ ZOOSYMPOSIA.7.1.24. [Link]

Savriama, Y., 2018: A step-by-step guide for geometric morphometrics of floral symmetry. Front. Plant Sci., 9, doi: 10.3389/fpls.2018.01433. [Link]

Savriama, Y. and S. Gerber, 2018: Geometric morphometrics of nested symmetries unravels hierarchical interand intra-individual variation in biological shapes. Sci. Rep., 8, 12, doi: 10.1038/s41598-018-36147-z. [Link]

Schlüter, N., 2016: Ecophenotypic variation and developmental instability in the Late Cretaceous Echinoid $\mathrm{Mi}$ craster brevis (Irregularia; Spatangoida). PLOS ONE, 11, e0148341, doi: 10.1371/journal.pone.0148341. [Link]

Schmidinger, L., 2014: Geometric Morphometrics of Clypeasteroids. Master Thesis, Universität Wien.

Schultz, H. A. G., 2017: Echinoidea: With Bilateral Symmetry, Irregularia, Berlin, De Gruyter, Boston, 359 pp, doi: 10.1515/9783110368536. [Link]

Seilacher, A., 1979: Constructional morphology of sand dollars. Paleobiology, 5, 191-221, doi: 10.1017/ s0094837300006527. [Link]

Sheets, H. D., 2001: Integrated Morphometrics Package (IMP), CoordGen8-Coordinate Generation Utility \& PCAGen8-Principal Components Generation Utility.

Sievers, D. and J. H. Nebelsick, 2014: The petalodium of clypeasteroid sand dollars: A geometric morphometric description of shape and comparison of fossil and living species. The Paleontological Society Special Publications, 13, 49-50.

Stanton, R. J., J. R. Dodd, and R. R. Alexander, 1979: Eccentricity in the clypeasteroid echinoid Dendraster: Environmental significance and application in Pliocene paleoecology. Lethaia, 12, 75-87, doi: 10.1111/ j.1502-3931.1979.tb01246.x. [Link]

Swisher, R. E. and J.-P. Lin, 2019: A geometric morphometric analysis of Arachnoides placenta (Echinoidea: Clypeasteroida): An examination of ontogenetic development and morphological variation. Zoosymposia, 15, 159-171, doi: 10.11646/zoosymposia.15.1.18. [Link]

Telford, M., 1981: A Hydrodynamic Interpretation of Sand Dollar Morphology. Bull. Mar. Sci., 31, 605-622.

Webster, M. and H. D. Sheets, 2010: A practical introduction to landmark-based geometric morphometrics. The Paleontological Society Papers, 16, 163-188, doi: 10.1017/S1089332600001868. [Link]

Zachos, L. G., 2015: Holistic morphometric analysis of growth of the sand dollar Echinarachnius parma (Echin odermata:Echinoidea:Clypeasteroida). Zootaxa, 4052, 151-179, doi: 10.11646/zootaxa.4052.2.1. [Link]

Zelditch, M. L., 2005: Developmental regulation of variability. In: Hallgrimsson, B. and B. K. Hall (Eds.), Variation: A Central Concept in Biology, Academic Press, New York, 249-276, doi: 10.1016/B978-0120887774/50014-4. [Link]

Zelditch, M. L., D. L. Swiderski, H. D. Sheets, and W. L. Fink, 2004: Geometric Morphometrics for Biologists: A Primer, Academic Press, New York, 443 pp, doi: 10.1016/B978-0-12-778460-1.X5000-5. [Link]

Zelditch, M. L., D. L. Swiderski, and H. D. Sheets, 2012: Geometric Morphometrics for Biologists: A Primer, Second Edition, Academic Press, San Diego, 478 pp, doi: 10.1016/C2010-0-66209-2. [Link] 